\title{
A figuração feminina na poesia surrealista de Louis Aragon
}

\section{Marinice Argenta* Maria Luiza Berwanger da Silva**}

É preciso que a poesia seja 'alma falando à alma', que o sonho substitua o 'pensar dirigido', que as imagens não sejam mais o fogo fátuo que corre à superfície dos pensamentos ou dos sentimentos, mas relâmpagos, iluminando a todo o instante 'as cavernas do ser'. [...] o poeta de hoje não só o é sempre, como também de objeto se torna sujeito: aquele 'que inspira'. Não é mais apenas 'eco sonoro', 'vidente'; é tudo isso ao mesmo tempo, e mais ainda: mágico. É ele que muda a vida, o mundo, que transforma o homem. Sabe 'mesclar a ação ao sonho', 'confundir o interior e o exterior', 'encerrar a eternidade ao instante', 'fundir o geral no particular'. Faz do homem à sua imagem uma unidade indestrutivel. Faz do homem e do mundo um só diamante. [...] Os poetas surrealistas,

[...] assistem maravilhados ao fluxo de uma fonte viva, inexaurivel, arrastando pepitas por entre a lama. Aquilo que oferecem não pode ser comparado com o que se fez antes deles.

Maurice Nadeau, História do Surrealismo, 1964.

Resumo: O Surrealismo emerge com uma proposta de liberdade de expressão fundamentada em teorias freudianas, transportando alguns conteúdos psicanalíticos no desenvolvimento dessa estética. Assim, a escrita automática, que busca no inconsciente humano os sentimentos considerados reais pelos surrealistas, será a prática para uma nova linguagem literária. Destarte, para verificar essa nova proposta artística, far-se-á uma análise do poema Les yeux d'Elsa, de Louis Aragon, através do qual se evidencia a construção da imagem feminina nesse processo apregoado pelos Surrealistas.

Palavras-chave: Análise do discurso. Surrealismo. Imagem feminina.

\footnotetext{
* Doutoranda em Literatura na Universidade Federal do Rio Grande do Sul (UFRGS). É professora de Literatura da Universidade Regional Integrada do Alto Uruguai e das Missões do Campus de Frederico Westphalen, RS (URI/FW), e professora de Língua Portuguesa e Estrangeira no Instituto Federal de Educação, Ciência e Tecnologia Farroupilha, campus de Frederico Westphalen, RS (IFFar/FW). http://orcid.org/oooo-0003-2180-8159/ mariniceargenta@gmail.com

** Professora do Programa de Pós-Graduação em Letras da Universidade Federal do Rio Grande do Sul (UFRGS) e doutora em Letras pela Universidade Federal do Rio Grande do Sul (1995) com Pós-Doutorado em Literatura Comparada pela Université de la Sorbonne-Nouvelle, Paris. http://orcid.org/oooo-ooo18280-8633/ marialuizaberwanger@gmail.com
}

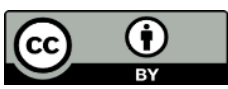

Este artigo está licenciado sob forma de uma licença Creative Commons Atribuição 4.0 Internacional, que permite uso irrestrito, distribuição e reprodução em qualquer meio, desde que a publicação original seja corretamente citada. 


\begin{abstract}
The Surrealism emerges with a proposal for freedom of expression based on Freudian theories, carrying some psychoanalytic content in the development of this aesthetic. Therefore, automatic writing, which searches the human unconscious for feelings considered real by the surrealists, will be decisive practice for a new literary language. Thus, in order to verify this new artistic proposal, an analysis of the poem Les yeux d'Elsa by Louis Aragon will be made, through which the construction of the female image developed in this process proclaimed by the Surrealists is evidenced.

Keywords: Discourse analysis. Surrealism. Female image.

Résumé: Le Surréalisme émerge avec une proposition de liberté d'expression basée sur les théories freudiennes, transportant un contenu psychanalytique dans le développement de cette esthétique. Alors, l'écriture automatique, qui recherche dans l'inconscient humain les sentiments jugés réels par les surréalistes, sera la pratique déterminante d'un nouveau langage littéraire. Donc, pour vérifier cette nouvelle proposition artistique, une analyse du poème Les yeux d'Elsa de Louis Aragon sera faite, à travers laquelle la construction de l'image féminine développée dans ce processus proclamé par les surréalistes est attesté.
\end{abstract}

Mots-clefs: Analyse du discours. Surréalisme. Image féminine.

\title{
Introdução
}

A poesia para os surrealistas é constituída como um dos pilares de luz na busca da liberdade tão almejada pelos artistas desta expressão, isto é, ela, junto à liberdade e ao amor, seria iluminadora dos caminhos que abririam portas para a libertação do espírito humano “contra a alienação da sociedade” (REBOUÇAS, 1986, p. 17).

O Surrealismo nasce, então, com a tentativa de libertar o homem de todas as amarras sociais que o impedem de ser livre, de pensar por si e em si mesmo, propondo uma espécie de revolução cultural que deveria ir contra toda a ordem vigente, as antigas formas de pensamento, ou seja, uma proposta de cunho anarquista que compreende uma crítica às ideias de autoria, de estilo, de representação. Segundo os pressupostos estéticos do Surrealismo, o homem deveria tomar consciência de seus próprios desejos e desacorrentar-se de tudo que o impede de realizar tal propósito (ARGENTA, 2007). A liberdade de expressão torna-se, assim, a finalidade primordial dessa nova estética, como se apreende nas palavras de Breton (1985, p. 35) "só o que me exalta ainda é a única palavra: liberdade". 
Inseridas nessa proposta de liberdade para os surrealistas, surgem, no início do século XX, as teorias psicanalíticas de Sigmund Freud, as quais se tornam uma solução para a expressão desejada, uma vez que André Breton - um dos fundadores do movimento - sente-se fortemente influenciado pelos conteúdos apresentados na época por Freud - criando, inclusive, grupos de estudos -, transportando muitos desses conteúdos para a expressão artística que começa a eclodir nesse momento. Como nos apresenta no Manifesto Surrealista:

\begin{abstract}
Ainda vivemos sob o império da lógica. [...] Mas os procedimentos lógicos, em nossos dias, só se aplicam à resolução de problemas secundários. $\mathrm{O}$ racionalismo absoluto que continua em moda não permite considerar senão fatos dependendo estreitamente de nossas experiências. [...] Ao que parece, foi por puro acaso que recentemente trouxe à luz uma parte do mundo intelectual, a meu ver, a mais importante, e da qual se afetava não querer saber. Agradeçase isso às descobertas de Freud. Com a fé nestas descobertas desenha-se afinal uma corrente de opinião, graças à qual o explorador humano poderá levar mais longe suas investigações, pois que autorizado a não ter só em conta as realidades sumárias. Talvez esteja a imaginação a ponto de retomar seus direitos (BRETON, 1985, p. 40).
\end{abstract}

A psicanálise, então, apresenta-se como uma nova leitura inserida nessa estéticaliterária. Todavia, é importante salientar que as pesquisas de Breton a respeito da teoria freudiana sobre a representação do sonho não se dirigiram no intento de realizar uma análise psicanalítica, mas para suprir o interesse de encontrar, nestas teorias, o alicerce sobre o qual irá construir a linguagem literária surrealista.

Dessa forma, as teorias de Freud começam a apresentar, para os surrealistas, um material de extrema importância para a estruturação do movimento. Encontram aí a chave para a sua libertação artística: o Inconsciente, que acreditam trazer à tona os sentimentos reais que se encontram submersos, através da Escrita Automática (ARGENTA, 2007), como podemos observar em "Segredos da Arte Mágica Surrealista”, no primeiro manifesto de Breton:

Mande trazer com que escrever [sic], quando já estiver colocado no lugar mais favorável possível para concentração do seu espírito sobre si mesmo. Ponha-se no estado mais passivo, ou receptivo, dos talentos de todos os outros. Pense que a literatura é um dos mais tristes caminhos que levam a tudo. Escreva depressa, sem assunto preconcebido, bastante depressa para não reprimir, e para fugir à tentação de se reler. A primeira frase vem por si, tanto é verdade que a cada 
segundo há uma frase estranha ao nosso pensamento consciente, pedindo para ser exteriorizada (BRETON, 1985, p. 62).

Buscando no Inconsciente os seus reais sentimentos, seus desejos reprimidos, o escritor estabelece uma espécie de comunicação com o irracional, com o ilógico, de forma deliberada, através da "escrita automática", para trazê-los à tona como forma de libertação de toda pressão social exercida, rompendo as barreiras limitadoras impostas por uma civilização que acredita em sua realidade como única e verdadeira. Dessa forma, expressa-se a partir de seus impulsos mais primitivos, que se encontram no inconsciente (ARGENTA, 2007).

Destarte, para melhor exemplificar e identificar estes procedimentos surrealistas extraídos das teorias freudianas e desencadeados em suas expressões artísticas, encaminhemo-nos para a análise de um poema surrealista denominado Les yeux d'Elsa, do livro "Les Yeux d'Elsa” (1942) do poeta francês Louis Aragon.

Louis Aragon foi um escritor francês que percorreu os caminhos da prosa e da poesia, além de trabalhar também na área jornalística. Nasceu em o3 de outubro de 1897, em Paris, na França. Além de ter sido colega de André Breton na Faculdade de Medicina da Universidade de Paris, participaram juntos também do movimento dadaísta. Mais tarde, dirigiram a revista Littérature juntamente com Philippe Soupault, a qual já começa a apresentar os indícios de uma nova estética; fato que se confirma mais adiante quando, junto com André Breton e Paul Éluard, colabora para a criação e edificação do movimento surrealista.

Sua estreia como poeta ocorre em 1920, com o livro "Feu de Joie", após isso, seguiram-se muitas outras publicações, dentre elas "Les yeux d'Elsa” (1942), a qual apresenta o poema que será aqui investigado. Sua poesia é inspirada no amor que dedica à sua esposa Elsa Triolet - também uma importante escritora Russa, do início do século XX (POETICA, 2008). 
Seu material poético volta-se para a liberdade estética, na qual dá vazão à fantasia, à imaginação, ao pensamento onírico. Há uma liberdade de linguagem com um vocabulário de fácil acessibilidade para a leitura do poema, apontando-nos mais uma característica da poesia moderna, que acabou por conduzi-lo a uma estética voltada para os traços surrealistas.

Esse poema, Les yeux d'Elsa, tem sua classificação como gênero lírico, desprovido, porém, da pureza do lírico clássico, uma vez que o poema se desdobra com traços de outros gêneros, o que vem de imediato caracterizar a poesia moderna surrealista, a qual apresenta uma desvinculação de regras na sua composição, uma vez que se utiliza da "escrita automática”, primeiro fator determinante dessa estética, que foi totalmente embasado nas teorias freudianas estudadas por Breton (1985), o qual as apresentou aos poetas, erigindo a "atmosfera surrealista" (BRETON, 1985, p. 71) através dessa forma específica e genuína de escrever dos surrealistas, a qual, segundo Breton,

[...] presta-se especialmente à produção das mais belas imagens. Pode-se dizer até que as imagens aparecem nesta corrida vertiginosa como guiões [sic] únicos do espírito. Aos poucos o espírito se convence da suprema realidade das imagens. Limitando-se no começo a lhes prestar sujeição, logo ele percebe que lisonjeiam sua razão, aumentam, outrossim, seu conhecimento. Ele toma conhecimento dos espaços ilimitados onde se manifestam seus desejos, onde se reduzem sem cessar o pró e o contra, onde sua obscuridade não o atraiçoa. Ele vai, conduzido por essas imagens que o seduzem, que apenas lhe dão tempo para soprar os dedos queimados. É a mais bela das noites, a noite dos fulgores: perto dela, o dia e a noite (BRETON, 1985, p. 71, grifo do autor).

Sendo assim, “o importante nesse procedimento é o que ele revela enquanto afloramento da linguagem interior do sujeito" (REBOUÇAS, 1986, p. 40-41), ou seja, "no ato da criação, o poeta incorpora, simultaneamente, os domínios do sonho, do mágico e do maravilhoso" (p. 42), como poderemos perceber no próprio poema que será analisado a seguir. 
Esse poema, Les yeux d'Elsa, faz parte de uma das poesias do livro "Les yeux d'Elsa”, do grande artista surrealista Louis Aragon, o qual foi publicado em 1942, pela editora SEGHERS, de Paris, e está inserido em uma coleção denominada Collection "P.S.". Esta editora foi criada primeiramente para publicar somente livros de poesia.

\section{Les yeux d'Elsa}

Tes yeux sont si profonds qu'en me penchant pour boire

J'ai vu tous les soleils y venir se mirer

S’y jeter à mourir tous les désespérés

Tes yeux sont si profonds que j'y perds la mémoire

A l'ombre des oiseaux c'est l'océan troublé

Puis le beau temps soudain se leve et tes yeux changent

L'été taille la nue au tablier des anges

Le ciel n'est jamais bleu comme il l'est sur les blés

Les vents chassent em vain les chagrins de l'azur

Tes yeux plus clairs que lui lorsqu'une larme y luit

Tes yeux rendent jaloux le ciel d'après la pluie

Le verre n'est jamis si bleu qu'à as brisure

Mère des Sept douleurs ô lumière mouillée

Sept glaives ont percé le prisme des couleurs

Le jour est plus poignant qui point entre les pleurs

L'iris troué de noir plus bleu d'être endeuillé

Tes yuex dans le malheur ouvrent la double brèche

Par où se reproduit le miracle des Rois

Lorsque le coeur baltant ils virent tous les trois

Le manteau de Marie accroché dans la creche 
Une bouche suffit au moin de Mai des mots

Pour toutes les chansons et pour tous les hélas

Trop peu d'un firmament pour des millions d'astres

Il leur fallait tes yeux et leurs secrets gémeaux

L’enfant accaparé par les belles images

Ecarquille les siens moins démesurément

Quand tu fais les grands yeux je ne sais si tu mens

On dirait que láverse ouvre des fleurs sauvages

Cachent-ils des éclairs dans cette lavande où

Des insects défont leurs amours violents

Je suis pris au filet des étoiles filantes

Comme un marin qui meurt em mer en plain mois d'août

J'ai retire ce radium de la pechblende

Et j’ai brûlé mês doigts à ce feu défendu

O paradis cent fois retrouvé reperdu

Tes yeux sont mon Pérou ma Golconde mês Indes

Il advint qu'un beau soir l'univers se brisa

Sur des récifs que les naufrageurs enflammèrent

Moi je voyais briller au-dessus de la mer

Les yeux d'Elsa les yeux d'Elsa les yeux d'Elsa

(ARAGON, 1942, p. 33-34)

Por intermédio desse poema, adentraremos pelos caminhos da expressão artístico-poética surrealista, no sentido de captarmos os traços fundamentais que a constituem, bem como examinaremos a tão idealizada liberdade de expressão. Momento em que perscrutaremos no poema o surgimento de uma distinta imagem feminina, ou 
seja, que se apresenta e que se personifica como surrealista, isto é, que se insere nessa nova visão despojada das regras pré-estabelecidas, uma vez que, em um primeiro olhar, afigura-se como imagem de mulher tradicional ou mesmo recorrente. Destarte, o poema será o instrumento para uma certa perscrutação a respeito da figuração feminina no Surrealismo.

Les yeux d'Elsa trata-se de um poema de classificação pertencente ao gênero lírico, todavia percebe-se imediatamente que se afasta do lírico clássico, uma vez que já em sua primeira leitura percebe-se a ausência total de pontuação, o que caracteriza, incontinenti, a poesia moderna. Sendo assim, já se percebe o traço moderno surrealista em sua composição, uma vez que a libertação de regras pré-estabelecidas já se faz notória em sua própria estrutura formal. No entanto, há ainda alguns traços clássicos quando nos referimos à rima, pois ela está presente em todas as estrofes, não de forma sequencial, mas, em algumas delas, aparece como rimas interpoladas, como podemos constatar na primeira estrofe, com boire no final do primeiro verso, rimando com mémoire no final do quarto verso; e mirer no final do segundo verso, rimando com désespérés no final do terceiro verso:

Tes yeux sont si profonds qu'en me penchant pour boire

J'ai vu tous les soleils y venir se mirer

S'y jeter à mourir tous les désespérés

Tes yeux sont si profonds que j’y perds la mémoire

Em outras estrofes, apresenta-nos as rimas misturadas, como podemos perceber, na segunda estrofe, a rima entre troublé do primeiro verso com blés do quarto verso, e nenhuma rima entre o segundo e terceiro verso, através das palavras changent e anges:

A l'ombre des oiseaux c'est l'océan troublé

Puis le beau temps soudain se leve et tes yeux changent

L'été taille la nue au tablier des anges

Le ciel n'est jamais bleu comme il l'est sur les blés 
Sendo assim, percebe-se também que a constituição da forma é caracterizada por um poema de dez estrofes, sendo cada uma formada por quatro versos, o que o mantém atrelado, de certa forma, a um estilo clássico. A linguagem é constituída por um vocabulário fluido, compreensível e descomplicado, o que manifesta, portanto, mais uma vez a poesia moderna. Poderíamos dizer, baseando-nos em seus aspectos estruturais, que, na nossa classificação poética, estaria inserido como um poema da segunda geração do modernismo, o qual ainda mantém alguns aspectos da primeira geração - que foi fortemente influenciada pelas correntes vanguardistas. Todavia, o traço forte da segunda geração é efetivamente contundente, pois sua estrutura é mais elaborada em sua constituição.

O papel da imagem vem aqui representado de forma assaz significativa, uma vez que a imagem feminina no surrealismo, em sua construção e representação, em um primeiro momento, parece seguir um modelo tradicional. E essa imagem que emerge, aparentemente, e mesmo paradoxalmente, parece manter-se em uma representação recorrente de imagem feminina, mesmo diante das propostas vanguardistas propagadas pelo Surrealismo, as quais pregavam uma ruptura com todos esses aspectos tradicionais vigentes na sociedade da época.

Quando observamos uma imagem feminina em uma obra surrealista, em um primeiro momento, podemos realmente depararmo-nos com aspectos bem tradicionais, clássicos ou mesmo românticos - no sentido de construção idealizada. Todavia, apesar dessa primeira impressão, essa imagem feminina poderá nos apresentar aspectos que vão ao encontro das propostas surrealistas. É o que nos propomos a verificar no decorrer desta análise. Assim, não ficaremos atrelados a uma linguagem em um sentido textual linear, mas aos elementos que caracterizam uma linguagem da própria imagem, a qual se tornou uma espécie de síntese para os surrealistas, uma vez que a imagem para esses artistas seria, segundo Gérard Durozoi,

[...] a negação da dissociação lógica das coisas, ela manifesta a sua profunda unidade num campo de vidência dos qual os verdadeiros poetas serão os exploradores. Ela significa a reconciliação das coisas entre si, o incentivo da reconciliação do homem com todas as coisas, com o universo.

[...] A imaginação dos poetas não deixa, com efeito, de se divertir com as aparências exteriores do real: eles metamorfoseiam qualquer coisa numa outra, 
invertem a ordem dos processos, metem até ao ridículo a irrevogável sucessão da vida e da morte. Eis, por exemplo, G. Hugnet celebrando a vitória do desejo sobre a realidade: "o homem vê, nestas imagens naturais, imagens dele, a alquimia de suas recordações, dos seus delírios... Ele vive as suas alucinações, as alucinações que existem, que foram vividas algures. Vive" (DUROZOI, 1976, p. 202-203).

Sendo assim, para os surrealistas, a imagem estabelece-se no campo da representação, seja pela visão ou pelo sonho, uma vez que se instaura pela sua pluralidade, de forma polissêmica, "uma criação pura do espírito" (REVERDY, 1918 apud DUROZOI, 1976, p. 202), que não poderá originar-se de uma comparação, mas de uma aproximação de realidades distintas, buscando uma unidade entre esses opostos, relacionando-os, no sentido de "comunicar a cada um deles, qualquer que seja, um vigor que lhe faltava enquanto considerado isoladamente" (DUROZOI, 1976, p. 203). Assim, realidade e irrealidade formam uma indissolúvel unidade.

A imagem da mulher vem aqui, então, como a grande musa inspiradora para os surrealistas. Nas escritas automáticas de Breton, por exemplo, à mulher é facultada a imagem de poder, de sensualidade, como também a concepção de "salvação terrestre". Além da sua vocação transcendente, de sua irracionalidade sobre o racional masculino - o que nos faz perceber de imediato a ideia dessa irracionalidade reportada ao processo inconsciente. Segundo Durozoi, a mulher, para os surrealistas, "realiza, com efeito, a paradoxal missão de mergulhar o homem na pele material do corpo e de lhe abrir simultaneamente o mundo das revelações maravilhosas" (DUROZOI, 1976, p. 219), como uma espécie de mediadora entre os mundos real e irreal, contribuindo para o artista em sua jornada ao mundo surreal.

Segundo Durozoi, para os surrealistas, "as mulheres são fadas que dão sentido ao mundo, quer dizer, que confiam as suas chaves aos poetas: 'Quando o destino te enviou ao meu encontro, pousava em mim a maior sombra e posso dizer que foi em mim que essa janela se abriu'” (DUROZOI, 1976, p. 220). Assim, os surrealistas consideram a figura feminina como uma espécie de força transformadora, como um ser que se encontra mais próximo da irracionalidade, do sonho, de todos esses fatores que se encontram atrelados ao mundo inconsciente; uma espécie de intercâmbio entre o sonho e a realidade; operando, assim, como uma "musa que pode conduzir os homens até a criatividade 
artística" (BRADLEY, 1999, p. 47), ou seja, atuando como uma catalizadora ou mesmo um pretexto para a realização de suas obras.

Partindo desse pressuposto é que adentraremos em uma análise verificativa, no sentido de perscrutar essa construção imagética da mulher no mundo surrealista, que compreende as suas práticas artísticas desenvolvidas diante "dos principais objetos de seus questionamentos, tais como o amor, a poesia, a liberdade, a revolução, o inconsciente, a mulher, o erotismo, o sonho, o acaso-objeto e a magia, etc" (LIMA, 1995, p. 15); no sentido de avultar essa correspondência teórico-prática e sua decorrência nas obras artísticas surrealistas, tendo como escopo a imagem feminina e sua representação por meio da arte surrealista.

E, para iniciarmos essa verificação, partiremos do próprio título da obra, o qual já nos fornece subsídios para adentrarmos nessa verificação e compreensão. Destarte, através do título Les yeus d'Elsa [Os olhos de Elsa], apreende-se que o poema se desenvolverá sobre os olhos de uma mulher, e uma mulher específica: Elsa, o homônimo da própria mulher de Louis Aragon. Nesse título, também temos a enunciação do tema, ou seja, os olhos de uma mulher específica, o que nos ajudará a perscrutar essa construção de figura feminina.

No decorrer de todo o poema, o eu lírico fará alusão a esses olhos, os olhos de Elsa, como poderemos perceber já nos primeiros versos da primeira estrofe,

Tes yeux sont si profonds qu'en me penchant pour boire

J'ai vu tous les soleils y venir se mirer

S'y jeter à mourir tous les désespérés

Tes yeux sont si profonds que j’y perds la mémoire

[Teus olhos são tão profundos que neles inclino-me para beber

Vi todos os sóis neles se refletirem

Neles jogarem-se à morte todos os desesperados 
Teus olhos são tão profundos que neles eu perco a memória] ${ }^{1}$

Nesses primeiros versos, percebemos a reverência do eu lírico aos olhos de Elsa, que se inclina para bebê-los, devido à sua profundidade. E já nesse momento nota-se que, através dos olhos dessa mulher, o eu lírico mergulha no mundo do inconsciente, e esse "mergulho" é propiciado pelos olhos da mulher. Essa percepção faz-se notória quando passamos para o segundo verso "vi todos os sóis neles se refletirem”, uma vez que o eu lírico adentra em uma outra realidade.

Essa entrada no mundo inconsciente apresenta-nos uma forte característica surrealista, ao mesmo tempo em que se pode entrever a técnica da escrita automática, pois os sentidos dos versos atentam-nos para uma desconexão de ideias, como se o eu lírico estivesse deixando seus dedos correrem sobre o papel, soltando frases advindas do inconsciente. A presença dos olhos de Elza torna-se aqui, portanto, a grande condutora para essa submersão ao mundo inconsciente.

Apreende-se também a construção de realidades distintas, no momento em que o eu lírico inclina-se na profundidade dos olhos, como se fossem um lago profundo, unindo o real com o irreal e construindo uma nova realidade, que é concebida pelo leitor de forma ordinária. Elemento esse de suma importância para o surrealismo, pois aqui se cria a faísca para a criação transformadora de duas realidades diferentes para a formação de uma única.

Percebe-se também a criação de uma realidade ampliada pela sua imaginação por meio do verso "vi todos os sóis neles se refletirem", ou seja, esta ampliação do real, no qual “todos os sóis" se refletem, remete-nos ao "merveilleux, o maravilhoso” (BRADLEY, 1999, p. 9) dos surrealistas, pois, à medida que a realidade é ampliada, ela cria uma visão que transcende e, desse modo, ultrapassa as barreiras dos modos de pensar preestabelecidos. Fator importante para os artistas surrealistas, pois confronta um modo de pensar tradicional em uma época em que predomina a racionalidade.

\footnotetext{
${ }^{1}$ Tradução nossa. Importante salientar que a tradução completa do poema foi realizada com o intuito de efetivar a análise desse poema, e não como tradução de uma poesia em português para uma publicação literária. Desta forma, não houve a preocupação em formar as rimas, conforme o poema original em francês apresenta.
} 
Há aqui também uma relação entre o merveilleux surrealista e o sublime de Kant, pois, para o filósofo, à medida que o homem amplia sua imaginação diante da grandeza da Natureza, sente-se impotente, porque a razão estabelece uma barreira, uma espécie de bloqueio que o impede de apreciá-la através dos sentidos. Porém, no instante em que reconhece essa impotência - que lhe causa medo - transforma-a por meio do sentimento sublime, o qual o desperta para a consciência de sua superioridade diante da Natureza, ou seja, consciência de poder que o conduz para além da percepção comum, apontando para a ideia de sublimidade (DUARTE, 1997). Pontualmente o traço característico do surrealismo, pois buscavam essa amplitude da realidade, gerada pela estimulação da imaginação humana diante da Natureza.

Por conseguinte, percebe-se que, ao mesmo tempo em que o poeta sente o merveilleux dos surrealistas ou mesmo o sublime de Kant, essa ampliação grandiosa da Natureza cria um distanciamento da realidade, fazendo-o caminhar pelo mundo do sonho, criando novos sentimentos e, assim, estimulando sua imaginação.

No terceiro verso, o eu lírico nos apresenta os olhos de Elza também com realidades distintas, ou seja, tornam-se uma espécie de rio, de oceano, no qual as pessoas se jogam à morte, corroborando para a presença de características próprias do surrealismo, ou seja, realidades distintas, ao mesmo tempo em que a profundidade deles faz o eu lírico perder a memória.

Identifica-se, portanto, já nessa primeira estrofe, uma considerável presença de características surrealistas, nas quais a figura feminina perfaz um papel assaz significativo, uma vez que, mesmo nos parecendo um tanto idealizada, é através dela que o eu lírico parte para o estado onírico dos surrealistas, permitindo ao poeta que, através de seus olhos, situe-se entre o real e o sonho. Trata-se aqui, também, de uma supervalorização da mulher, na medida em que a própria imagem da mulher é ampliada, através do merveilleux. E, mesmo apresentando certa conotação romântica, de beleza, perfeição e até mesmo idealização por meio de seus olhos, o poeta a avulta, engrandecendo-a, expandindo-a, tornando a própria mulher surreal, ou seja, atinge-se o merveilleux postulando-a na surrealidade, libertando-a, assim, dos conceitos preestabelecidos, na medida em que está além da mulher comum. 
A l'ombre des oiseaux c'est l'océan troublé

Puis le beau temps soudain se leve et tes yeux changent

L'été taille la nue au tablier des anges

Le ciel n'est jamais bleu comme il l'est sur les blés

[Na sombra dos pássaros um oceano turbulento

Depois um tempo bom se ergue subitamente e teus olhos se modificam

O verão poda as nuvens como batas de anjos

O céu nunca é tão azul como sobre o trigo]

Nessa segunda estrofe, o eu lírico nos apresenta versos que estimulam a imaginação do leitor, na medida em que aponta somente para a "sombra" dos pássaros, o que já o faz imaginar de imediato os próprios pássaros voando sobre o oceano turbulento, criando, assim, esboços de imagens que permitiram o desenvolvimento completo da cena pelo próprio leitor, ofertando-nos com mais uma característica surrealista. E o próprio oceano turbulento nos remete novamente para o merveilleux, para a ideia de ampliação e grandiosidade da Natureza. Percebe-se também uma entrada no processo onírico, na medida em que percebemos os confrontos estabelecidos entre real e irreal, criando uma surrealidade, tão almejada pelos surrealistas. Fato constatado por Duplessis, quando nos aponta para a arte surrealista:

A arte, como as narrativas oníricas, é um dos sinais pelos quais o inconsciente se exprime, uma vez que reflete o mistério da alma e do mundo. $\mathrm{O}$ fato de cada artista empregar sempre um símbolo em vez de outro, traduz o que André Breton chama de "personalidade de escolha" reveladora do eu profundo. Não se deve desprezar nenhum meio de interpretação do Supra-real, pois cada um revela um de seus aspectos. A "linguagem da revelação fala, ao mesmo tempo, de diversos lados, umas palavras mais alto, outras mais baixo. É preciso resignar-se em apreendê-las através de trechos esparsos" (DUPLESSIS, 1963, p. 108).

Observamos aqui, por conseguinte, essa conjunção entre sonho e realidade, que foi concebida através da escolha de um objeto específico, os olhos de uma mulher, que propiciam ao artista o desvelamento do seu eu profundo, refletindo seu inconsciente, 
desfazendo-se do senso crítico, rompendo com os traços tradicionais e transcendendo para outras realidades.

Nos próximos versos, da terceira estrofe, o artista parte para as assimilações dos olhos da mulher com os aspectos da Natureza.

Les vents chassent em vain les chagrins de l'azur

Tes yeux plus clairs que lui lorsqu'une larme y luit

Tes yeux rendent jaloux le ciel d'après la pluie

Le verre n'est jamis si bleu qu'à as brisure

[Os ventos em vão procuram tristezas no azul

Teus olhos são mais claros que ele quando neles brilha uma lágrima

Teus olhos deixam o céu enciumado após a chuva

O vidro nunca é tão azul quando em pedaços]

Em vista disso, percebe-se que os olhos de Elsa se encontram “misturados" aos aspectos da Natureza, como se estivessem presentes nela mesma, ou seja, como se fizessem parte da própria Natureza. O que nos faz perceber que o eu lírico não se encontra em uma realidade definida, mas dominado já por uma espécie de devaneio, propiciado pelos olhos de Elsa. Nessa esfera de irrealidade, sua imaginação vai se desenvolvendo de forma totalmente livre, na qual mistura os olhos da mulher com aspectos da Natureza, momento em que se entrega aos pensamentos oníricos, concretizando, então, uma forte característica surrealista.

Os olhos de uma mulher, nesse contexto, são o fator catalizador para essa entrada no mundo inconsciente. São os olhos de Elsa que o inspiram, ou mesmo o beneficiam para a busca do surreal. Fator que nos remete, por sua vez, à importância da imagem feminina para os artistas surrealistas e, principalmente, essa ampliação de sua imagem, essa relevância de seus olhos para o desenvolvimento desses aspectos.

Nota-se, destarte, que a imagem feminina está além de uma mera idealização, de uma construção de endeusamento, de encanto, deificação, uma vez que esses olhos o transportam para além de uma realidade construída tradicionalmente, pois o conduz 
para outras realidades, aquelas que estão além de uma singela, comum, habitual, fazendo-o adentrar no mundo surreal.

Percebem-se aqui também transformações de espaços temporais, ou seja, "após a chuva”, os olhos de Elsa transformam a própria Natureza, dando-a uma personificação, o que transforma até mesmo o eu lírico, dando-lhe o ensejo para a construção imaginária para além do onírico, como se o aprofundasse cada vez mais para o nível inconsciente. Assim, percebemos que, nos últimos dois versos, o poeta penetra em um estado de total divagação, como se estivesse devaneando nesse estado onírico, com uma frase desconexa sobre outros elementos, como o vidro em pedaços e sua cor mais azul, e todos esses estados são propiciados pelos olhos de Elsa, não apenas no sentido de avultar esse olhar, mas de ampliá-lo, de dar-lhe força e amplitude, mostrando seu poder.

Seguindo com a quarta estrofe, temos uma referência à Maria, uma vez que, pela cultura cristã, veneram-se as sete dores da Virgem Maria, a qual, de acordo com essa cultura, sofreu as dores sem desespero.

Mère des Sept douleurs ô lumière mouillée

Sept glaives ont percé le prisme des couleurs

Le jour est plus poignant qui point entre les pleurs

L'iris troué de noir plus bleu d'être endeuillé

[Mãe das Sete Dores ó luz ungida

Sete espadas perfuram o prisma das cores

O dia é mais pungente que os pingos entre lágrimas

As manchas negras da íris são mais azuis enlutadas]

Essa referência das sete dores de Maria encontra-se imediatamente relacionada com "sete" espadas, as quais, ao perfurarem as cores com os aspectos dolorosos, decompõe sua luz, retirando-lhes o brilho, referindo-se metaforicamente à dor sentida por Maria, tornando o dia ainda mais doloroso que a própria dor exprimida pelas lágrimas, fato que torna o olhar de Elsa mais intenso e brilhoso, ou seja, seus olhos não se deixam fraquejar pelo sofrimento, mas tornam sua cor mais intensa, como se se 
tornasse mais forte diante das adversidades. Fato que nos apresenta, mais uma vez, a fortaleza do olhar de Elsa, transportando tal circunstância ao próprio valor da imagem da mulher, isto é, sua contundente fortaleza interior, a qual transporta o eu lírico para outras realidades comparativas, liberando-o da mentalidade crítica, fazendo-o discorrer de forma espontânea, sem preconcepções, liberando, assim, uma profusão de empregos metafóricos em sua linguagem artística, apresentando-nos, dessa forma, muitos aspectos surrealistas, como o merveilleux, as realidades opostas, o mergulho no inconsciente, a escrita automática, o sonho e a realidade em um só momento, transformando-se em suprarrealidade. Esse cenário pode ser constatado também no quinto verso, quando nos diz:

Tes yuex dans le malheur ouvrent la double brèche

Par où se reproduit le miracle des Rois

Lorsque le coeur baltant ils virent tous les trois

Le manteau de Marie accroché dans la creche

[Teus olhos no revés abrem-se em par

Por onde se reproduz o milagre dos Reis

Quando o coração batendo foi visto pelos três

O manto de Maria estendido sobre a manjedoura]

Aqui, os olhos de Elza, além de já terem sido desapossados da dor, como aludido na estrofe anterior, abrem-se para o próprio milagre, no sentido de superação de atribulações ou infortúnios, e abrem-se "em par", no intuito de alargarem-se, de ampliarem-se, ao invés de fecharem-se para o revés. Essa ampliação reporta-nos ao merveilleux, novamente, ao mesmo tempo em que as realidades, entre os olhos de Elsa, o milagre dos Reis e o manto de Maria sobre a manjedoura, conectam-se em um só momento, transcendendo, assim, a própria realidade.

Para o eu lírico, portanto, são os olhos de Elsa que lhe trazem toda essa profusão de realidades e sonhos, hibridificadas, amalgamadas entre si, cada uma revelando seus aspectos, mas tornando-se uma realidade surreal. 
Compreende-se, assim, que a imagem feminina vai sendo construída nos versos não somente de forma divinizada ou supervalorizada, mas, para além disso, no sentido de dar à mulher - aqui através de seus olhos - um poder além daquele lírico-poético arrebatado e sentimental do Romantismo, pois, além de ser possuidora de todos esses atributos, que parecem colocá-la em um pedestal - aspecto bem tradicional e romântico -, é através dela que esses fatores surrealistas podem ser desencadeados, ou seja, será por meio da imagem feminina que o artista adentrará em seu inconsciente e construirá seu mundo surreal.

Adentrando nos versos da sexta estrofe, percebemos mais uma vez a referência à Maria, uma vez que o poeta cita o mês de maio, mês esse também relacionado à Santa cristã.

Une bouche suffit au moin de Mai des mots

Pour toutes les chansons et pour tous les hélas

Trop peu d'un firmament pour des millions d'astres

Il leur fallait tes yeux et leurs secrets gémeaux

[Basta uma boca para as palavras de Maio

Para todas as canções e todas as desventuras

Tão pouco firmamento para os milhões de estrelas

Precisavam de teus olhos e seus segredos geminados]

O eu lírico, assim, apresenta-nos que uma só boca - referindo-se à de Maria seria suficiente para as coisas boas e ruins ao mesmo tempo. Todavia, para os milhões de estrelas, os olhos de Elsa necessitariam de pouco firmamento, uma vez que, juntamente com seus segredos, é que dariam espaço para os milhões de estrelas. Assim, constata-se que os olhos de Elsa é que dimensionariam o firmamento, criando, novamente, uma grandiosidade, uma importância dimensionada para os olhos de Elsa, tornando-os fator propulsor para essa grandeza e vastidão. Essa magnitude em torno da Natureza mostra-nos o merveilleux manifestando-se, mais uma vez, nos versos do artista. 
Importante salientar que o merveilleux é o intuito final dos surrealistas e, para chegar a ele, o artista utiliza-se de vários recursos, como a entrada no inconsciente, o estado onírico, entre outros, e a própria imagem da mulher, aqui representada pelo seu olhar. Destarte, é a própria mulher, aqui nesse poema, que é a catalizadora para todos esses estados psíquicos.

Constata-se, por conseguinte, que a imagem feminina não se limita à própria imagem em si, mas conduz o poeta para esse mundo tão almejado da arte surrealista, uma vez que necessita desse olhar para chegar ao merveilleux.

Nessa sétima estrofe, o poeta nos oferta uma comparação entre os olhos ingênuos com os dissimulados, como podemos perceber a seguir.

L'enfant accaparé par les belles images

Ecarquille les siens moins démesurément

Quand tu fais les grands yeux je ne sais si tu mens

On dirait que láverse ouvre des fleurs sauvages

[A criança absorvida pelas belas imagens

Arregala os seus de forma menos díspar

Quando tu arregalas teus olhos não sei se mentes

Dizem que uma chuva forte abre as flores silvestres]

Nesses versos, o eu lírico nos oferece a ideia de que, sob o olhar ingênuo de uma criança, quando é despertada por imagens que lhe agradam, percebe-se uma admiração que os tornam abertos de forma sincera para tal acontecimento, ou seja, seus olhos não conseguem esconder seu encantamento diante de tal imagem. No entanto, para o poeta, quando os olhos de Elsa se arregalam, eles o deixam confuso, duvidoso, tornando-se incompreensíveis, sem que ele saiba exatamente o que dizem; fato que nos leva a pensar que não há ingenuidade em seus olhos, eles podem estar dissimulando, escondendo emoções, o que nos faz inferir que são mais experientes ou mesmo possuem mais vivência, são olhos versados, calejados, conhecedores do mundo. E o fato de deixar o poeta oscilando entre o que eles realmente significam instiga o artista em seus 
pensamentos, levando-o para a divagação de um acontecimento da natureza, saindo do devaneio causado pelo seu olhar, como se se deslocasse da percepção dos olhos de Elsa para entrar em outro mundo, o da percepção externa, oscilando, assim, entre o real e o devaneio, propiciando ao artista o desenvolvimento da poesia livre, liberta da subordinação tradicional, característica pontual para os surrealistas. Dessa forma, repetidamente, percebe-se a importância da imagem da mulher para o extravasamento da escrita poética e toda a sua dinamização para a realização de tal intento.

É o que podemos constatar também na estrofe seguinte, na qual o poeta, agora, mescla os olhos de Elsa como propulsores tanto de acontecimentos da Natureza como de seus próprios devaneios.

Cachent-ils des éclairs dans cette lavande où

Des insects défont leurs amours violents

Je suis pris au filet des étoiles filantes

Comme un marin qui meurt em mer en plain mois d'août

[Eles escondem relâmpagos nesta flor de lavanda onde

Os insetos se desfazem em seus amores violentos

Estou preso na rede de estrelas cadentes

Como um marinheiro que morre no mar em meados de agosto]

Aqui, a força dos olhos de Elsa, mesmo escondidos em meio às flores, instiga o comportamento de insetos, ao mesmo tempo em que deixa o poeta aprisionado no universo, sentindo-se como um ser que fenece; avultando, portanto, ainda mais o poder magnético desse olhar, que acaba por conduzi-lo ao devaneio, uma vez que essa imagem do olhar causa-lhe um estranhamento, e é essa sensação de "estranhamento (dépaysement) que faz os olhos se abrirem para a realidade absoluta" (REBOUÇAS, 1986, p. 23, grifos do autor), que não é a realidade habitual, na qual vivemos, mas uma realidade que transcende, uma suprarrealidade, tão almejada pelos surrealistas - o merveilleux. 
Mais uma vez, portanto, a imagem do olhar de uma mulher transporta o poeta para o germinar da poesia, para o enaltecimento do sonho mesclado à realidade, como uma espécie de desdenho a uma realidade usual, conferindo-lhe supremacia e domínio sobre o artista. Através desses versos da nona estrofe, apreende-se o impulso propulsor da força do olhar de Elsa sobre o poeta.

J'ai retiré ce radium de la pechblende

Et j’ai brûlé mês doigts à ce feu défendu

O paradis cent fois retrouvé reperdu

Tes yeux sont mon Pérou ma Golconde mês Indes

[Eu removi a radiação da pechblenda

E queimei meus dedos neste fogo proibido

Ó paraíso cem vezes encontrado e perdido

Teus olhos são meu Peru, minha Galconda, minhas Índias]

No momento em que cita a "pechblenda" - um minério que foi a base da descoberta da radioatividade, o qual emite forte luz capaz de atravessar objetos -, o eu lírico nos aponta que, por esse olhar, ele fez sacrifícios, sofreu um martírio, a ponto de queimar-se fisicamente, apontando aqui para uma forte característica romântica, ou seja, a faina do cavaleiro para esse olhar da mulher, ou seja, para a própria mulher representada pelo poder de seu olhar. Todavia, mesmo aparentemente apresentando essa imagem idealizada, é através dela que se desenrola a própria poesia; ela, a mulher, é o estopim para o desencadeamento da poesia pretensamente desconexa, fora da razão, uma vez que ela mesma é a propulsora instigadora que propicia essa arte poética que liga, como uma ponte, "o mundo da realidade cotidiana com o mundo maravilhoso, e essa ponte é a única para quem deseja conservar a lucidez" (ALQUIÉ, 1977 apud REBOUÇAS, 1986, p. 23), segundo a visão dos surrealistas, ou seja, a fusão do real e do imaginário, a tão almejada realidade absoluta, ou mesmo a suprarrealidade.

$\mathrm{Na}$ estrofe a seguir, o artista apresenta o nascimento desse olhar, que se faz de forma sublime, dado que foi criado pelo próprio universo. 
Il advint qu'un beau soir l'univers se brisa

Sur des récifs que les naufrageurs enflammèrent

Moi je voyais briller au-dessus de la mer

Les yeux d'Elsa les yeux d'Elsa les yeux d'Elsa

[Numa noite linda o universo irrompe

Sobre os recifes que os náufragos conflagraram

Eu vi brilhar por sobre o mar

Os olhos de Elsa, os olhos de Elsa, os olhos de Elsa]

No primeiro verso, o eu lírico descreve uma noite bela sob a qual se desencadeou a explosão do universo, referindo-se ao nascimento desse olhar de Elsa, fazendo-nos pensar sobre o nascimento desse olhar despontando de forma sublime, uma vez que o próprio universo o criou e o fez de forma tão dimensionada que atinge o oceano inteiro, brilhando acima dele, reportando-nos, de forma repetida, a uma ampliação da natureza e, por conseguinte, novamente para o merveilleux, fato que aponta fortemente para essa característica recorrente, neste poema, do movimento surrealista. E, para finalizar, reitera a grandeza, a dimensão, o poder desse olhar, repetindo três vezes "os olhos de Elsa”.

Podemos constatar, por fim, que, diante da análise desse poema, percebe-se que tanto na estrutura quanto na linguagem poética, a fidelidade, em relação às características propostas pelo movimento, é mantida genuinamente. Os traços surrealistas são peremptoriamente perceptíveis no decorrer de todo o poema.

Com relação à imagem feminina, em um primeiro olhar, parece-nos que permanece a mesma. Porém, se nos detivermos de maneira mais acurada nesse objetivo desejado pelos surrealistas, com relação ao escopo pretendido e à imagem figurada, perceberemos que não é a imagem em si o grande objetivo almejado, mas tudo que ela compreende, ou seja, ver a imagem e captar o que está além dela mesma, isto é, a mulher como catalizadora que impulsiona o artista para a realização de seu discurso poético. Assim, essa figura feminina, mesmo sendo apresentada de forma tradicional ou 
romântica, portadora de beleza e perfeição, idealizada e assentada em um pedestal, não é valorizada sob esses únicos aspectos, mas além deles, ou seja, considera-se que há uma força existente nela - nessa poesia representada através dos olhos. Sendo assim, esse poder existente na imagem da mulher, figurado em seus olhos, é que conduz o artista para outros mundos, o do sonho, do inconsciente, de realidades distintas, as quais se entrepõem para criar a "centelha" do inconsciente, ampliando seus significados para alcançar o merveilleux; é que perfaz a finalidade última dos surrealistas, "o maravilhoso é sempre belo, qualquer maravilhoso é belo, só mesmo o maravilhoso é belo" (BRETON, 1985, p. 45).

Deparamo-nos, então, por meio da verificação analítica, com a construção dessa figura feminina na poesia surrealista, ou seja, ela mantém alguns aspectos tradicionais, bem como românticos, e são eles que nos fazem crer na perpetuação de um modelo tradicional. Todavia, quando analisamos por meio de traços particulares que perfazem o movimento surrealista, consideramos uma outra leitura, a qual está além de uma leitura tradicional, pois se percebe que a figura feminina se faz presente não somente como uma imagem em si, mas como grande catalizadora para a realização artística, como a faísca condutora para os caminhos do inconsciente, ou seja, a figura feminina é representada como uma dinamizadora para além do mundo cotidiano. E era esse o grande desejo dos surrealistas, ou seja, implementar a crítica à realidade e à própria razão, combatendo as certezas e criando uma realidade superior, uma suprarrealidade.

\section{Referências}

ARAGON, Louis. Les Yeux d'Elsa. Paris: SEGUERS, 1942. (Collection “P.S.” SEGUERS). ARGENTA, Marinice. Simbolismo, Surrealismo e Fantástico: homologias e divergências em suas expressões artístico-literárias. In: Biblioteca Digital Mackenzie. Dissertação (Mestrado em Letras) Universidade Presbiteriana Mackenzie, São Paulo, 2007. Disponível em: <http://tede.mackenzie.br/jspui/handle/tede/2146? $\mathrm{mod}=$ full $>$. Acesso em: 14 de setembro de 2018 . 
BRADLEY, Fiona. Surrealismo. São Paulo: Cosac \& Naify Edições, 1999.

BRETON, André. Manifestos do Surrealismo. São Paulo: Brasiliense, 1985.

DUARTE, Rodrigo. Parágrafos Selecionados da Crítica da Faculdade do Juízo de Immanuel Kant. In: O Belo Autônomo. Belo Horizonte: UFMG, 1997.

DUPLESSIS, Yves. O Surrealismo. $2^{\underline{a}}$ ed. Tradução de Pierre Santos. São Paulo: Difusão Europeia do Livro, 1963. (Coleção "Saber Atual”).

DUROZOI, Gerard. O Surrealismo: teorias, temas, técnicas. Portugal-Coimbra: Almedina, 1976.

LIMA, Sérgio. A Aventura Surrealista. Tomo I. Campinas, SP: Editora UNICAMP; São Paulo: UNESP; Rio de Janeiro: Vozes, 1995.

NADEAU, Maurice. História do Surrealismo. São Paulo: Perspectiva, 1985. (Coleção Debates: Arte).

POETICA: Poésie, poèmes et poètes. France: Société Oxyka SARL (ISSN 2649-2180). 2008. Disponível em: <https://www.poetica.fr/biographie-louis-aragon/>. Acesso em: 23 de janeiro de 2020.

REBOUÇAS, Marilda de Vasconcellos. Surrealismo. São Paulo: Ática, 1986. (Série Princípios).

Recebido em 10/10/2020. Aprovado em 19/o1/2021. 